\title{
Factorial significance on tractor stability under variation of terrain roughness employing the Taguchi method
}

\author{
Zhen $\mathrm{Li}^{1,2}$, Zhongxiang Zhu ${ }^{1,2}$, Jiahao Qin ${ }^{1,2}$, Enrong Mao ${ }^{1,2}$, Muneshi Mitsuoka ${ }^{3 *}$, \\ Eiji Inoue $^{3}$, Soyoung Shin ${ }^{3}$ \\ (1. College of Engineering, China Agricultural University, Beijing 100083, China; \\ 2. Beijing Key Laboratory of Optimized Design for Modern Agricultural Equipment, Beijing 100083, China; \\ 3. Faculty of Agriculture, Kyushu University, Fukuoka, 8120025, Japan)
}

\begin{abstract}
Tractor rollover accidents remain an issue with the development of agricultural mechanization. Adopting the scale-model-based experimental approach, this study investigated the three most influential geometric factors of tractor in various agricultural ground conditions with improved configuration of force sensing system. The initiation of tractor rollover, associated with the tire-ground contact status, was investigated for various front tire types, ballast weights, and rear track widths. Employing the Taguchi method, the ground reaction forces applied to the tractor's uphill wheels were measured and evaluated using stability indicators. By taking this approach, the effects and statistical significance of the three factors and their interactions were examined under various agricultural ground conditions. Results showed that the ballast weight significantly affected the ground contact status of the uphill front tire. The significance of the front tire type gradually increased as the road roughness increased, but dramatically decreased for an extremely rough road surface. Furthermore, none of the factors or interactions, except the factor of the rear track width for relatively rough roads, was statistically significant. The study revealed that not all commonly discussed factors consistently affect tractor stability. The results of the present study are thus expected to provide a reference explaining how to explore the necessity and feasibility of parameter adjustment before reconfiguring a tractor for higher stability.
\end{abstract}

Keywords: tractor rollover, scale model, agricultural fields, Taguchi method, factorial significance

DOI: $10.25165 /$ j.ijabe.20181105.3713

Citation: Li Z, Zhu Z X, Qin J H, Mao E R, Mitsuoka M, Inoue E, et al. Factorial significance on tractor stability under variation of terrain roughness employing the Taguchi method. Int J Agric \& Biol Eng, 2018; 11(5): 88-94.

\section{Introduction}

Tractor lateral rollover has been identified as a threat to the lives of operators performing modern agricultural activities ${ }^{[1]}$. Precautions, or predictions of tractor rollovers, are thus needed to allow operators to make precautious actions and to provide engineers a reference for improving stability. Pioneering investigations on the mechanism of tractor rollover have established fundamental theories explaining how a tractor behaves under certain ground conditions. The mathematical models thus generated further provide the basic concepts of consideration for tractors in dynamic, static, and quasi-static states ${ }^{[2-15]}$. Indicators of tractor stability obtained from mathematical models provide a simple way of describing vehicle stability. Such indicators are commonly used in assessing the general stability of tractors

Received date: 2017-08-12 Accepted date: 2018-05-16

Biographies: Zhen Li, PhD, Lecturer, research interests: safety and dynamics of agricultural machinery, Email: zhenli@cau.edu.cn; Zhongxiang Zhu, PhD, Associate Professor, research interests: design of intelligent agricultural machinery, Email: zhuzhonxiang@cau.edu.cn; Jiahao Qin, PhD candidate, research interests: tractor stability control, Email: qinjh@cau.edu.cn; Enrong Mao, PhD, Professor, research interests: design of intelligent agricultural machinery, Email: gxy15@cau.edu.cn; Eiji Inoue, PhD, Professor, research interests: agricultural machinery dynamics, Email: inoeiji@ bpes.kyushu-u.ac.jp; Soyoung Shin, Master candidate, research interests: safety and dynamics of agricultural machinery, Email: ssophieshin@gmail.com.

*Corresponding author: Muneshi Mitsuoka, PhD, Assistant Professor, research interests: vibration and stability of agricultural machinery. Faculty of Agriculture, Kyushu University, Fukuoka 812-0053, Japan. Tel: +81-92-6422929, Fax: +81-92-642-2929, Email: mitsuoka@bpes.kyushu-u.ac.jp. according to the forward speed, roll angle, transfer of lateral force, and acceleration at the center of gravity (COG) of a tractor ${ }^{[16-23]}$.

Borrowing from these fundamental theories, theoretical and experimental attempts have explored ways of improving tractor stability against rollover. By reconfiguring the tractor, mass distribution parameters (i.e., the tractor front-end weight and moment of inertia), vehicle structural parameters (i.e., front and rear track widths), and component properties (i.e., various properties of the tractor tire) have been shown to determine whether a tractor completely rolls over ${ }^{[24-38]}$. However, none of the cited studies attempted to stabilize a tractor from the initial stage of lateral rollover. Yet the relative importance of these parameters remains unknown because they have been analyzed separately as the sole variable in a single discussion.

Furthermore, tractor-safety-related studies consider different types of ground conditions. In most relevant research works, obstacles with designated shapes are preferred for the convenience of modelling, simulation, and verification. To stimulate stability abnormity for the further observation of behaviors, half-sine-curve-shaped, triangular, rectangular, and cobblestone-shaped obstacles are commonly used as part of an uneven road for the target tractor to travel over ${ }^{[39-42]}$. Meanwhile, earlier measurements made from a realistic perspective show a remarkable diversity of farming ground conditions and high randomness in road profiles ${ }^{[29-31]}$. Referencing the international standard ${ }^{[43]}$, it has been concluded that the various types of agricultural ground cover all degrees of road roughness so that all categories of agricultural roads should be concerned for a comprehensive study. There is thus no exact representative 
agricultural road profile with a specific level of roughness that is proper when describing the general issue of tractor rollover.

A recent study ${ }^{[44]}$ considered the factorial effects of several important parameters discussed in previous research works. They investigated the statistical significance of six important parameters affecting tractor dynamic stability and found three parameters that were influential. In their primary attempt, however, the setup of the force sensing units restricted the system such that the front and rear wheels could not be tested at the same time. The results accordingly reflected the stability variation assessed for a single uphill front or rear wheel. Furthermore, regarding the uneven ground condition, only two of eight classes of roads ( $E$ and $F$ ) in random profiles ${ }^{[43]}$ were introduced as representatives of the most typical types of ground for operating tractors. It thus remains unclear if these factors remain their significances when all types of agricultural ground are targeted.

The present study investigates the significant variations of three factors (i.e., the type of tractor front tire, ballast weight, and tractor rear width) important to tractor stability considering all road roughness classes ${ }^{[43]}$. Furthermore, we intend to build a more realistic scale-model-based system that allows simultaneous measurements of the ground reaction forces applied to the uphill front and rear wheels. Employing the orthogonal array L27, we also investigate the full factorial effects of the three factors including their interactions employing the Taguchi method. The results of the present study are expected to show the factorial effects of the three factors, and the tendencies of significance of all factors and their interactions under tests on random road surfaces in eight classes ${ }^{[43]}$. The aim of the study is to provide a reference explaining the necessity and feasibility of reconfiguring a tractor for higher stability against the initiation of rollover under different ground conditions.

\section{Materials and methods}

\subsection{Scale-model-based experimental system}

The present study considered the initiation of tractor rollover that completely relies on the contact condition between the tractor's uphill wheels and the sloping ground. Thus the stability indicators were proposed for the uphill front $\left(i_{o_{-}}\right)$and rear $\left(i_{o_{-}}\right)$ wheels, which are defined as:

$$
i_{o_{-} f / r}=\frac{F_{f / r_{-} u p}}{F_{\text {static } f / r_{-} u p}} \cdot 100
$$

It was thus necessary to measure the ground reaction forces applied to the uphill wheels. To serve a realistic purpose, as Figure 1 shows, the force sensing system built in this study mainly comprises a scale model tractor, scale random road surfaces, and force sensing units. We generated a medium lateral incline of 10 degrees. As the present study considered the tractor's uphill wheels, we used two sets of two force-sensing resistor (FSR) devices (FSR 408 model, Interlink Electronics) for the measurement of the two uphill wheels (i.e., one set of two FSRs was used for each wheel). Furthermore, two types of uneven tracks (shown in blue and grey in the Figure 1) were considered for the model tractor to travel over. The tracks in blue (four pieces, one beneath each wheel) served as the pre-run parts that stabilized the state of the model tractor before measurements. Their further application was to separate the active measuring areas (grey tracks) by the length of the tractor wheelbase. Setting the FSR devices under the uphill grey tracks then allowed simultaneous force measurements of the uphill front and rear wheels.

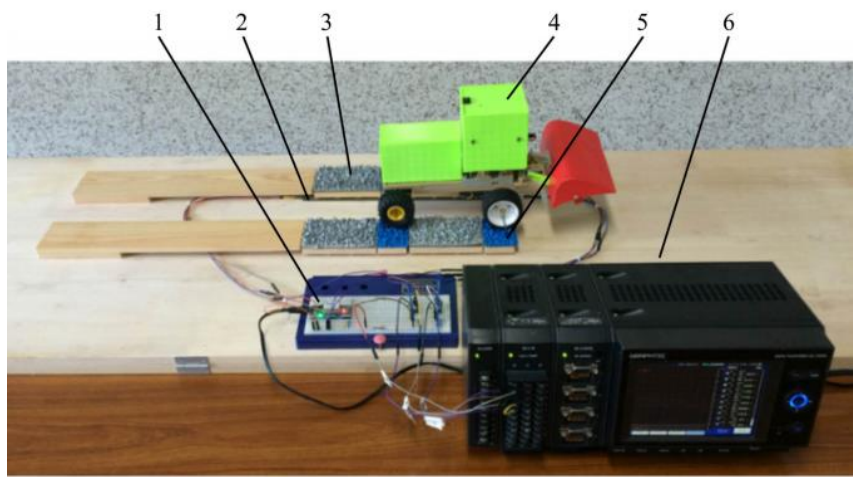

1. Circuit board 2. Force sensing resistor 3. Tested road surface 4. Scale model tractor 5. Pre-run road surface 6. Base board

a. System setup

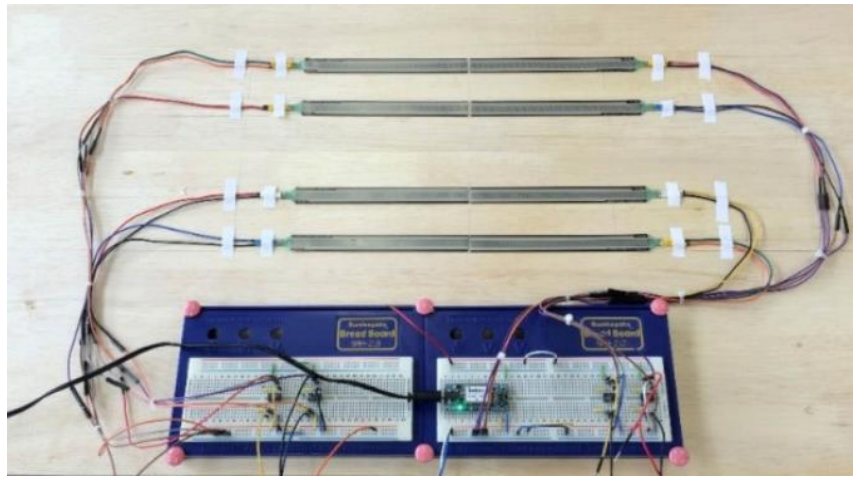

b. Sensor installation

Figure 1 Configuration of the scale-model-based sensing system

The FSR devices were built into the experimental system following the circuit shown in Figure 2. Each of the four FSR units occupied one channel of the data logger (Data Platform GL7000, GRAPHTEC). The summation of data for one measuring set (comprising two FSR devices) in a time series yielded the ultimate output of the dynamic ground reaction force applied to the corresponding uphill wheel.

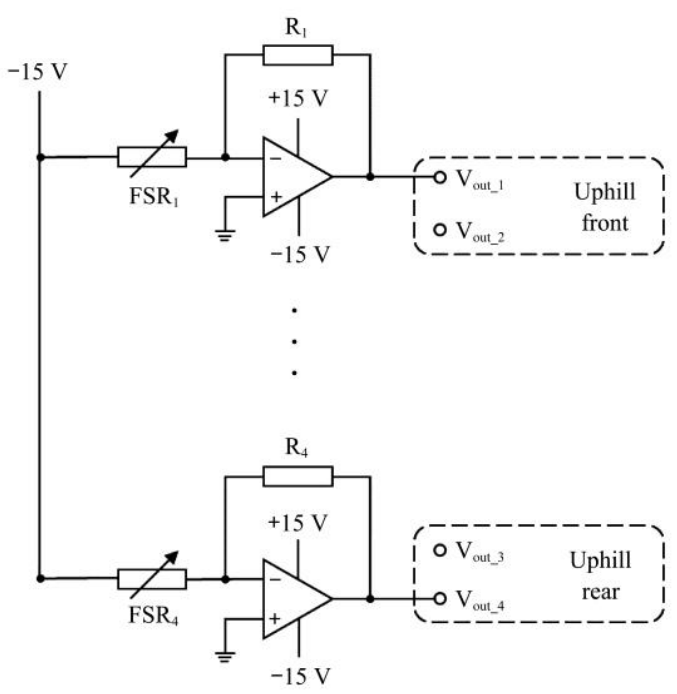

Figure 2 Circuit diagram for the FSR devices used in the force sensing system

This circuit yields a positive output swing of $0 \mathrm{~V}$ to $+15 \mathrm{~V}$ for each $v_{\text {out } j}$ following the equation:

$$
V_{\text {out }_{-} j}=15 \cdot\left(\frac{R_{j}}{R_{F_{S R_{-}} j}}\right)
$$

According to Equation (2), the output voltage that each parallel circuit produces is inversely proportional to the corresponding FSR 
resistance. Moreover, FSR devices possess the property that the resistance is approximately inversely proportional to the applied force. Voltage, as a result, is directly proportional to the force as the following equation describes:

$$
V_{\text {out } \_j}=k F_{j}
$$

Using a scale model tractor, three of the most significant physical parameters affecting the tractor rollover stability were studied, namely the type of tractor front tire, ballast weight, and tractor rear track width, as control factors. Important parameters of the scale model tractor are given in Table 1 .

Table 1 Specifications of the scale model tractor

\begin{tabular}{lc}
\hline \multicolumn{1}{c}{ Parameter } & Value \\
\hline Tractor wheelbase $/ \mathrm{mm}$ & 145 \\
Tractor forward speed $/ \mathrm{m} \cdot \mathrm{s}^{-1}$ & 0.2 \\
Implement weight $/ \mathrm{g}$ & 153 \\
Tractor weight $/ \mathrm{g}$ & 676 \\
Roll angle of the front axle $\left./{ }^{\circ}\right)$ & 11
\end{tabular}

Regarding the uneven road over which the model tractor travelled, surfaces in random profiles were considered to best represent various and complex off-road terrains ${ }^{[43]}$. Experimental and review studies ${ }^{[45-47]}$ indicated that tractor operating fields cover all eight road classes. It is therefore necessary to widen the investigation range of road classes with frequent and rare occurrences in terms of practical operating conditions. Therefore, the scale random surfaces in eight road classes for experiments were generated using the software MATLAB (R2015a) and Rhinoceros 5, and a three-dimensional printer CubeX Duo, as shown in Figure 3. The degree of road roughness gradually increases from class A to class $\mathrm{H}$.

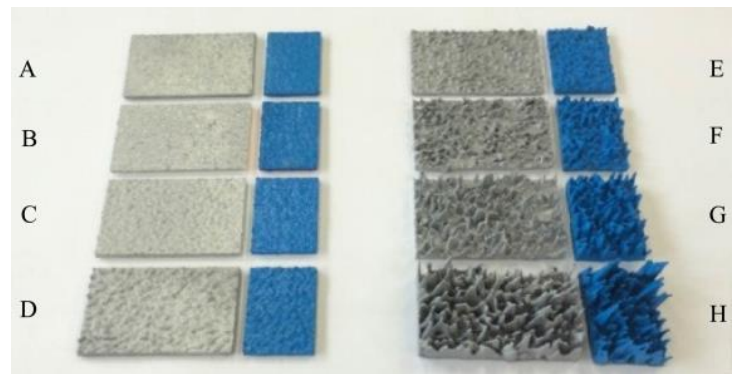

Figure 3 Samples of the scaled random road surfaces in all eight classes

\subsection{Design of experimental runs}

As has been identified under consideration of road classes $\mathrm{E}$ and $\mathrm{F}^{[44]}$, the type of tractor front tire and ballast weight are the most influential factors affecting the tire-ground contact state for the uphill front wheels, and the rear track width of a tractor predominantly affects the rear wheels. To further discuss their significance on all types of random terrains, we introduced these factors into discussion covering the full range of road roughness, as listed in Table 2. Factor I with three levels reflects physical tire properties of diameter and stiffness. Factor II represents the amount of additional weight applied to the tractor front end for stabilization. Factor III reflects the tractor configuration of a narrow, mid-range, or wide rear track width.

It should be noted that in this study, the COG forward shift was adjusted by adding frontal ballasts, the corresponding shift rate $S_{C O G}$ is defined as:

$$
S_{C O G}=\left[\left(l_{f}-l_{f}^{\prime}\right) / l_{f}\right] \cdot 100 \%
$$

While the Rear track width extension rate $E_{\text {rear }}$ is defined as:

$$
E_{\text {rear }}=\left[\left(w_{r}^{\prime}-w_{r}\right) / w_{r}\right] \cdot 100 \%
$$

Furthermore, not all the wheels (including the rear wheels) have lugged tread design. The wheels we used are not pneumatic ones, whose properties are indeed different from those of practical tractor tires. The approach proposed in this study is expected to provide qualitative analysis results showing if the factors dominate tractor stability in all types of terrain conditions.

When applying the Taguchi method, factor interactions may affect the system output more than the original factors. We therefore considered two-level interactions as virtual factors in this study. Correspondingly, the Taguchi orthogonal array L27 was employed to arrange the experimental runs, as shown in Table 3.

Table 2 Control factors and their levels involved in tractor configurations

\begin{tabular}{cccc}
\hline Level & Factor I (front tire) & Factor II $\left(S_{C O G}\right)$ & Factor III $\left(E_{\text {rear }}\right)$ \\
\hline 1 & $36 \mathrm{M}^{\mathrm{a}}$ & 0 & 0 \\
2 & $50 \mathrm{~L}^{\mathrm{b}}$ & $10 \%$ & $30 \%$ \\
3 & $50 \mathrm{H}^{\mathrm{c}}$ & $20 \%$ & $60 \%$ \\
\hline
\end{tabular}

Note: ${ }^{\text {a }}$ Tire $36 \mathrm{M}$ has a diameter of $36 \mathrm{~mm}$ and relatively middle stiffness $(298 \mathrm{~N} / \mathrm{m}) ;{ }^{\mathrm{b}}$ Tire $50 \mathrm{~L}$ has a diameter of $50 \mathrm{~mm}$ and relatively low stiffness $(152 \mathrm{~N} / \mathrm{m}) ;{ }^{\mathrm{c}}$ Tire $50 \mathrm{H}$ has a diameter of $50 \mathrm{~mm}$ and relatively high stiffness $(652 \mathrm{~N} / \mathrm{m})$.

\begin{tabular}{|c|c|c|c|c|c|c|c|c|c|}
\hline No. & I & II & $(\mathrm{I} \times \mathrm{III})_{1}$ & $(\mathrm{I} \times \mathrm{II})_{2}$ & III & $(\mathrm{I} \times \mathrm{III})_{1}$ & $(\mathrm{I} \times \mathrm{III})_{2}$ & $(\mathrm{II} \times \mathrm{III})_{1}$ & $(\mathrm{II} \times \mathrm{III})_{2}$ \\
\hline 1 & 1 & 1 & 1 & 1 & 1 & 1 & 1 & 1 & 1 \\
\hline 2 & 1 & 1 & 1 & 1 & 2 & 2 & 2 & 2 & 2 \\
\hline 3 & 1 & 1 & 1 & 1 & 3 & 3 & 3 & 3 & 3 \\
\hline 4 & 1 & 2 & 2 & 2 & 1 & 1 & 1 & 2 & 3 \\
\hline 5 & 1 & 2 & 2 & 2 & 2 & 2 & 2 & 3 & 1 \\
\hline 6 & 1 & 2 & 2 & 2 & 3 & 3 & 3 & 1 & 2 \\
\hline 7 & 1 & 3 & 3 & 3 & 1 & 1 & 1 & 3 & 2 \\
\hline 8 & 1 & 3 & 3 & 3 & 2 & 2 & 2 & 1 & 3 \\
\hline 9 & 1 & 3 & 3 & 3 & 3 & 3 & 3 & 2 & 1 \\
\hline 10 & 2 & 1 & 2 & 3 & 1 & 2 & 3 & 1 & 1 \\
\hline 11 & 2 & 1 & 2 & 3 & 2 & 3 & 1 & 2 & 2 \\
\hline 12 & 2 & 1 & 2 & 3 & 3 & 1 & 2 & 3 & 3 \\
\hline 13 & 2 & 2 & 3 & 1 & 1 & 2 & 3 & 2 & 3 \\
\hline 14 & 2 & 2 & 3 & 1 & 2 & 3 & 1 & 3 & 1 \\
\hline 15 & 2 & 2 & 3 & 1 & 3 & 1 & 2 & 1 & 2 \\
\hline 16 & 2 & 3 & 1 & 2 & 1 & 2 & 3 & 3 & 2 \\
\hline 17 & 2 & 3 & 1 & 2 & 2 & 3 & 1 & 1 & 3 \\
\hline 18 & 2 & 3 & 1 & 2 & 3 & 1 & 2 & 2 & 1 \\
\hline 19 & 3 & 1 & 3 & 2 & 1 & 3 & 2 & 1 & 1 \\
\hline 20 & 3 & 1 & 3 & 2 & 2 & 1 & 3 & 2 & 2 \\
\hline 21 & 3 & 1 & 3 & 2 & 3 & 2 & 1 & 3 & 3 \\
\hline 22 & 3 & 2 & 1 & 3 & 1 & 3 & 2 & 2 & 3 \\
\hline 23 & 3 & 2 & 1 & 3 & 2 & 1 & 3 & 3 & 1 \\
\hline 24 & 3 & 2 & 1 & 3 & 3 & 2 & 1 & 1 & 2 \\
\hline 25 & 3 & 3 & 2 & 1 & 1 & 3 & 2 & 3 & 2 \\
\hline 26 & 3 & 3 & 2 & 1 & 2 & 1 & 3 & 1 & 3 \\
\hline 27 & 3 & 3 & 2 & 1 & 3 & 2 & 1 & 2 & 1 \\
\hline
\end{tabular}

Table 3 Taguchi design of experiments based on the orthogonal array L27

Note: $\times$ represents the interaction between two factors.

The indicators $i_{o_{-} f}$ and $i_{o_{-} r}$ were used as system outputs for evaluations of tractor rollover intention referring to the uphill front and rear wheels, respectively. In accordance with the Taguchi method, we transformed the expression of Equation (1) as: 


$$
\frac{i_{o_{f}}}{r}=\left\{\begin{array}{lrl}
-M+N, & \text { if } \min _{t_{1} \leq t \leq t_{2}}\left(V_{f / r_{-} u p}\right)=0 \\
100 \min _{t_{1} \leq t \leq t_{2}}\left(\frac{V_{f / r_{-} u p}}{V_{\text {static_- } f / r_{-} u p}}\right)+N, & \text { if } \min _{t_{1} \leq t \leq t_{2}}\left(V_{f / r_{-} u p}\right)>0
\end{array}\right.
$$

where,

$$
N=\max (M)+1
$$

Accordingly, 216 (i.e., $27 \times 8$ ) experimental runs for each of the stability indicators were performed in the study.

\section{Results and discussion}

\subsection{Factorial effects on stabilizing the uphill front wheel against uplifting}

Figure 4 presents the main effects of the control factors I, II, and III on the mean value of $i_{o_{f}}$. The general trend is an evident decrease in $i_{o_{-}}$as the degree of road roughness rises. As a larger value of $i_{o_{-}}$indicates a better tire-ground contact condition, Figure 4a shows that level 2 of factor I $(50 \mathrm{~L})$ offers the model tractor greater safety regarding $i_{o f}$, especially for road classes $\mathrm{C}-\mathrm{G}$. Figure $4 \mathrm{~b}$ further reveals that level 3 of factor II $\left(20 \% S_{C O G}\right)$ significantly improves $i_{o_{f}}$. In Figure 4c, however, no level of factor III provides better stabilization of the uphill front wheel.

The measured signal-to-noise (SN) ratios of $i_{o_{-} f}$ for the control factors are shown in Figure 5. Generally, the SN ratio slightly
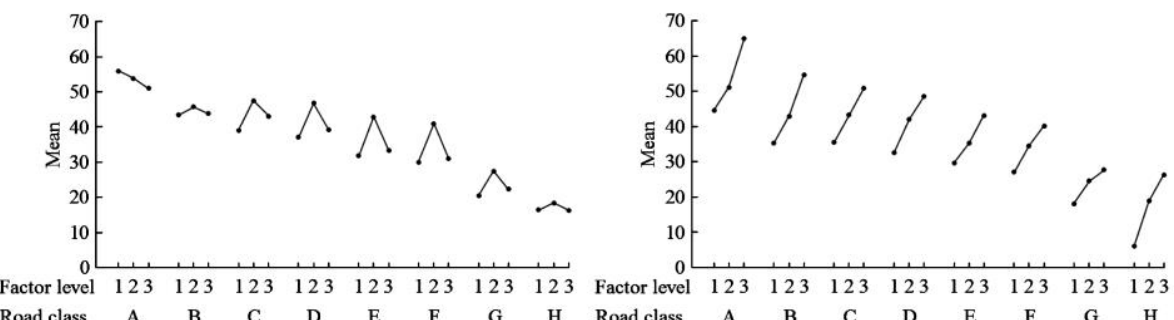

decreases with an increase in the degree of road roughness from class A to class $F$ but falls sharply for road classes $G$ and $H$. Following the larger-is-better principle, level 2 of factor I and level 3 of factor II were found to grant the uphill front wheel of the tractor better contact with the ground, as shown in Figures 5a and 5b. However, no level of factor III was confirmed to give larger values of the $\mathrm{SN}$ ratio for $i_{o_{-}}$, as shown in Figure $5 \mathrm{c}$.

Statistical results quantifying the statistical significances of the control factors and their interactions are given in Figure 6. The statistical significances of the factors and interactions in terms of affecting the mean and SN ratio of $i_{o f}$ clearly have similar results across the eight road classes. Factor I becomes more significant as its $P$ value approaches zero. Factor II was therefore found to be statistically significant in affecting the mean and data variation of a set of $i_{o_{f} f}$ values for all eight road classes. This conforms to the fact that tractor front ballast applies additional vertical forces to the front wheels, which amplifies $i_{o_{-}}$. Furthermore, the type of tractor front tire initially appears to be an ignorable factor when considered for road classes A and B (with $p$ values exceeding 0.05) However, it becomes increasingly significant as the degree of road roughness rises from class $\mathrm{C}$ to class $\mathrm{F}$. Dramatically, the significance of factor I falls again for road class $G$ and nearly disappears for road class H. Results further show that factor III and the interactions between two of the three control factors insignificantly affect $i_{o f}$.

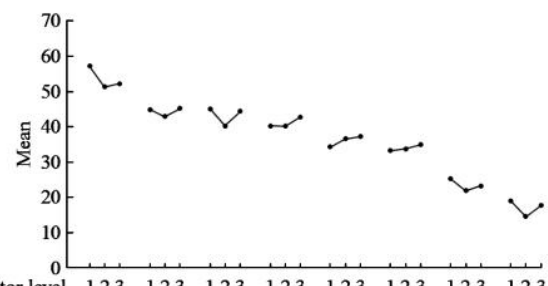

a. Results for factor I

b. Results for factor II

Figure 4 Main effects on the mean value of $i_{o f}$ in eight road classes

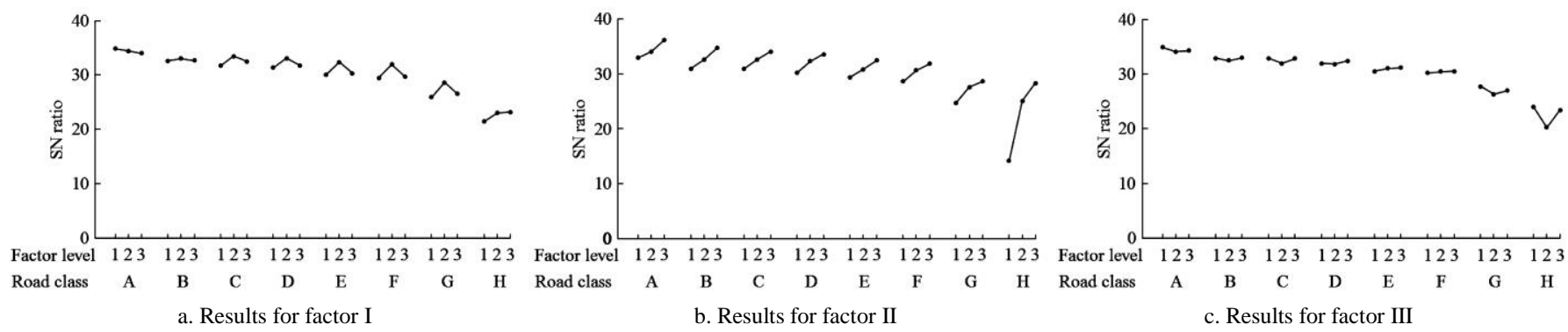

Figure 5 Main effects on the SN ratio of $i_{o_{-}}$in eight road classes

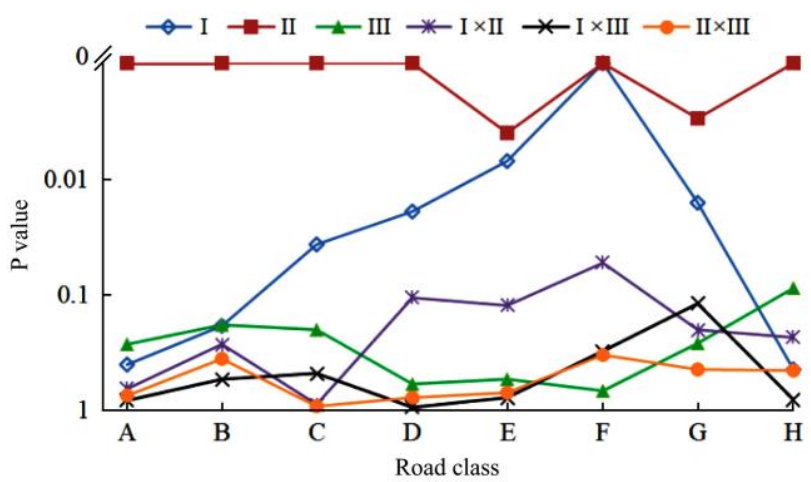

a. Factor significance for the mean of $i_{o_{-} f}$ versus road class

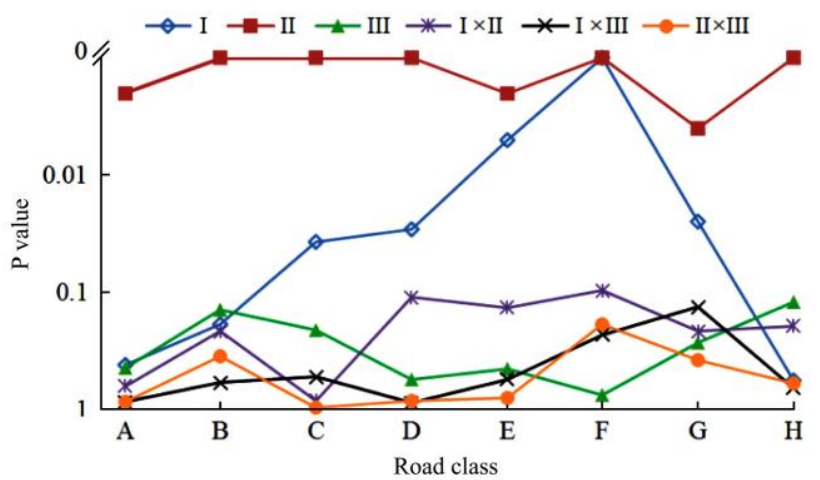

b. Factor significance for the SN ratio of $i_{o_{-} f}$ versus road class

Figure 6 Statistical significance of control factors and their interactions regarding $i_{o_{-} f}$ 


\subsection{Factorial effects on stabilizing the uphill rear wheel against uplifting}

The statistical analysis of the factorial effects on the mean value of $i_{o_{-} r}$ is presented in Figure 7. Results show that the condition of contact between the uphill rear wheel and the ground rapidly worsened on a road surface of class E or higher, irrespective of the control factor. However, a specific level of factor I or factor II has been demonstrated to have an overwhelmingly consistent consequence in terms of increasing $i_{o_{-}}$, as shown in Figures 7a and 7b. A similar conclusion is drawn for factor III regarding road classes A-D and $\mathrm{H}$. However, Figure 7c illustrates that level 3 of factor III $\left(60 \% E_{\text {rear }}\right)$ greatly increases $i_{o_{-} r}$ for road classes $\mathrm{E}-\mathrm{G}$.

Figure 8 presents the $\mathrm{SN}$ ratios of $i_{o_{-} r}$ varying with control factors and their levels. It is seen that irrespective of the factor and level, the $\mathrm{SN}$ ratio of $i_{o_{-} r}$ remains steady for road classes A-D. None of the changes to tractor front tire, ballast, or rear track width greatly affect the steadiness of the system output $\left(i_{o_{-}}\right)$ under these road conditions. The results for road classes E-F and $\mathrm{G}-\mathrm{H}$ can be categorized into another two groups with the $\mathrm{SN}$ ratio having a sustained downward trend. Figure $8 \mathrm{c}$ shows that level 3 of factor III enhances tractor stability in terms of $i_{o_{-} r}$ for road classes $\mathrm{E}-\mathrm{H}$.

Variations in statistical significances of the factors and interactions for $i_{o_{-} r}$ in different road classes are presented in Figure 9. It is interesting that the significance of factor III gradually rises initially at low degrees of road roughness (A-D). From road class E to class $\mathrm{G}$, the significance of factor III rapidly increases to a peak $P$ value of near zero, after which there is a dramatic drop in significance with $p$ values exceeding 0.05 for road class $\mathrm{H}$. Moreover, all other factors and interactions continue to have high $P$ values, indicating they are insignificant elements in terms of affecting $i_{o_{r}}$. Such a phenomenon implies that none of the investigated items dominates the ground contact condition of a tractor's uphill rear wheel on either an even or extremely rough road surface.

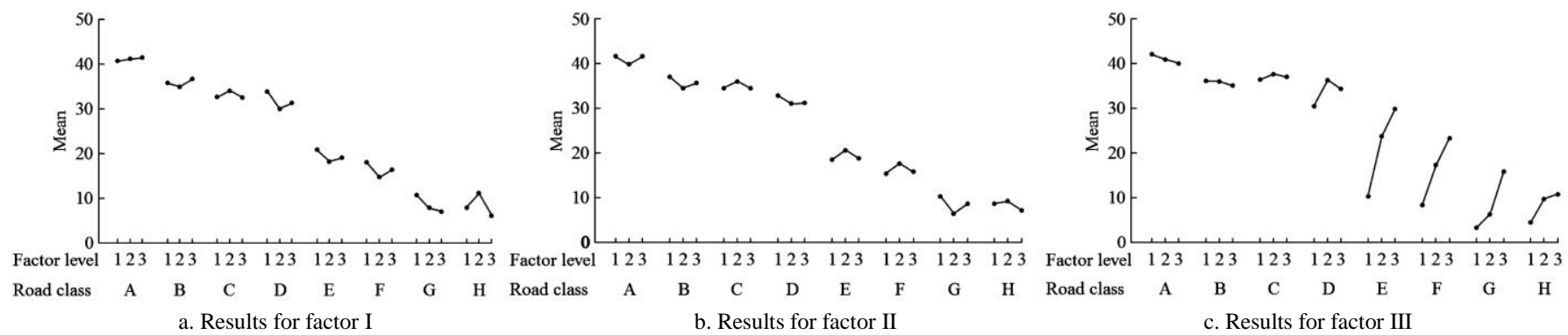

Figure 7 Main effects on the mean of $i_{o_{-} r}$ for eight road classes

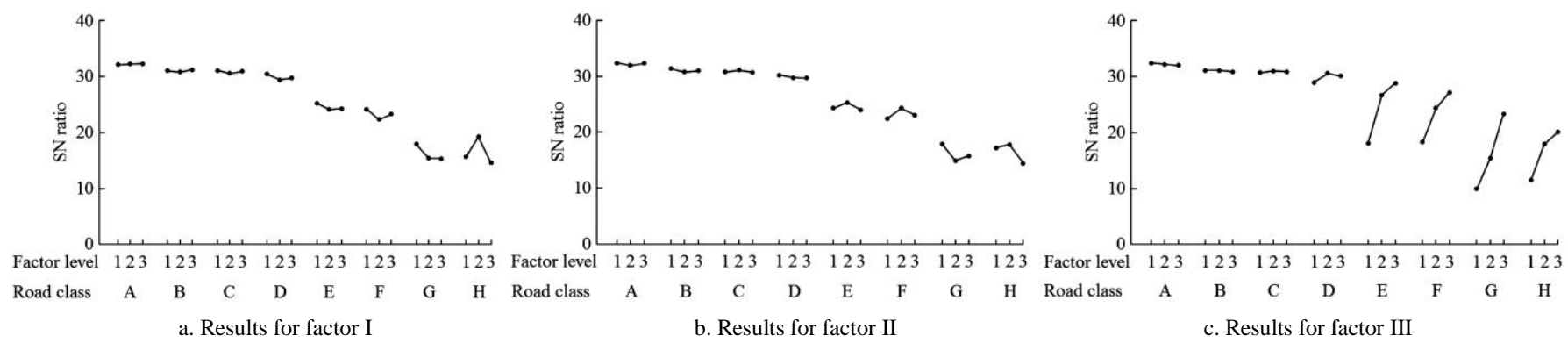

Figure 8 Main effects on the SN ratio of $i_{o_{-} r}$ for eight road classes

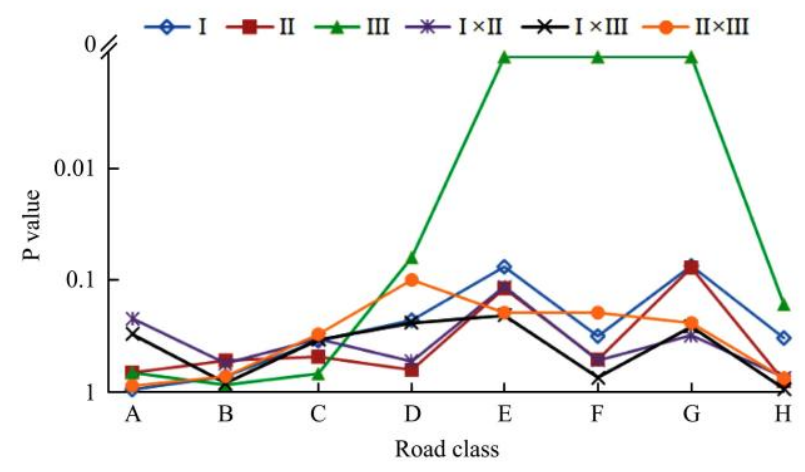

a. Factor significance for the mean value of $i_{o_{-} r}$ versus road class

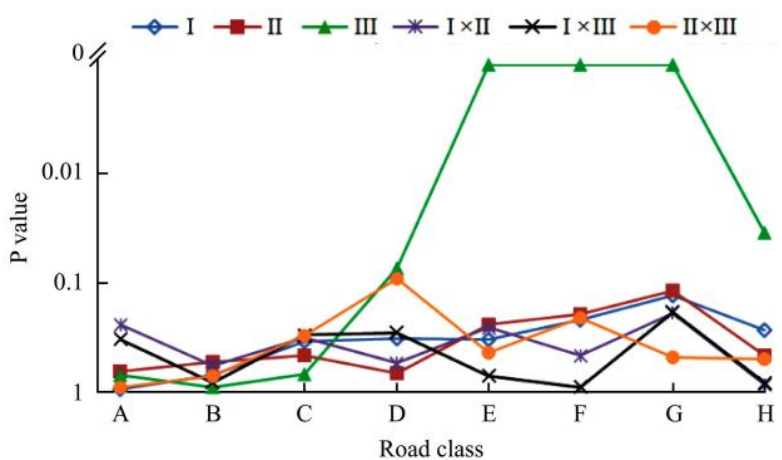

b. Factor significance for the $\mathrm{SN}$ ratio of $i_{o_{-} r}$ versus road class

Figure 9 Statistical significance of control factors and their interactions regarding $i_{o_{-} r}$

\section{Conclusions}

In this study, a force-sensing system allowing simultaneous measurements of ground reaction forces under both uphill wheels of the tractor was built and the variety of test roads was expanded to cover all eight road classes. This system was used to investigate the effects of the three control factors and the interactions between any two of them. The major conclusions can be obtained as follows:

(1) The results referring to the uphill front wheel revealed that the tractor front ballast was consistently highly significant for all eight road classes with the heaviest weight preferred. The tractor 
front tire type was found to gradually vary from an insignificant factor to a highly significant factor with the degree of road roughness rising. Furthermore, results show that a large front tire inflated at low pressure can generally be recommended to enhance the ground contact condition.

(2) Regarding the uphill rear wheel, only the factor of the rear track width tended to remarkably affect the tire-ground contact status under the road conditions of classes E to G. On road surfaces of class $\mathrm{H}$, the rear-tire-based stability of the tractor was predominantly determined by the high degree of road roughness. Therefore, none of the three major factors provided a physical configuration optimized on an H-class road.

(3) Statistical analysis on the factorial interactions regarding $i_{o_{-} f}$ and $i_{o_{-} r}$ showed their high $\mathrm{P}$ values on all types of terrains, implying that none of the interaction between two factors dominates the ground contact condition of any tractor tire neither on an even nor extremely rough road surface.

The results of the present scale-model-based study qualitatively and quantitatively described three major factors and their interactions in determining the initiation of a rollover for a tractor on a lateral incline. The approach and important findings of the study may provide engineers a reference for configuring a moving tractor of higher stability against rollover for operations under different road conditions.

\section{Acknowledgements}

The authors acknowledge the financial support received from The National Key Research and Development Program of China (2016YFD0700504) and the Fundamental Research Funds for the Central Universities of China (2018QC063).

\section{Nomenclatures}

Symbols

$E_{\text {rear }}$ Rear track width extension rate;

$F_{f / r_{-} u p}$ ground supporting force applied to the uphill front/rear tire, $\mathrm{N}$;

$F_{\text {static_ffr_up }}$ static-state ground supporting force applied to the uphill front/rear tire, $\mathrm{N}$;

$i_{o f / r} \quad$ uphill-front/rear-tire-based tractor stability indicator;

$k \quad$ coefficient between $v_{\text {out }}$ and $F$;

$l_{f} \quad$ original horizontal distance between the COG and the front axle when the tractor is not mounted with frontal ballast, $\mathrm{m}$;

$l_{f}^{\prime} \quad$ horizontal distance between the COG and the front axle when the tractor is mounted with frontal ballast, $\mathrm{m}$;

$M \quad$ number of data points indicating a zero value of the ground supporting force acting on an uphill tire;

$N$ cardinal number for results;

$R_{F S R_{-} j}$ force sensing resistor (FSR) $j, \Omega$;

$R_{j} \quad$ fixed resistor $j, \Omega$;

$S_{C O G}$ COG forward shift rate;

$V_{f / r_{-} u p}$ output voltage for the uphill front/rear tire, V;

$V_{\text {out } j}$ output voltage of the channel $j, \mathrm{~V}$;

$V_{\text {static_ffr_up }}$ static-state output voltage for the uphill front/rear tire, $\mathrm{V}$;

$w_{r} \quad$ original track width between the centers of the footprints of the rear tires, $\mathrm{m}$;

$w_{r}{ }^{\prime}$ track width between the centers of the footprints of the rear tires when the rear track width is changed, $\mathrm{m}$;

Abbreviations

COG center of gravity;

FSR force-sensing resister.

\section{[References]}

[1] Abubakar M S, Ahmad D, Akande F B. A review of farm tractor overturning accidents and safety. Pertanika Journal of Science and Technology, 2010; 18(2): 377-385.

[2] Abu-Hamdeh N H, Al-Jalil H F. Computer simulation of stability and control of tractor-trailed implement combinations under different operating conditions. Bragantia, 2004; 63(1): 149-162.

[3] Ahmed O B, Goupillon J F. Predicting the ride vibration of an agricultural tractor. Journal of Terramechanics, 1997; 34(1): 1-11.

[4] Ahokas J, Kosonen S. Dynamic behaviour of a tractor-trailer combination during braking. Biosystems Engineering, 2003; 85(1): 29-39.

[5] Baker V, Guzzomi A L. A model and comparison of 4-wheel-drive fixed-chassis tractor rollover during Phase I. Biosystems Engineering, 2013; 116(2): 179-189.

[6] Chisholm C J. A mathematical model of tractor overturning and impact behaviour. Journal of Agricultural Engineering Research, 1979; 24(4): 375-394.

[7] Chisholm C J. Analysis of rigid-body motion from cine film measurements. Journal of Agricultural Engineering Research, 1979; 24(4): 441-446.

[8] Chisholm C J. Experimental validation of a tractor overturning simulation. Journal of Agricultural Engineering Research, 1979; 24(4): 395-415.

[9] Davis D C, Rehkugler G E. Agricultural wheel-tractor overturns. Part I: Mathematical model. Transactions of the ASAE, 1974; 17(3): 477-483.

[10] Davis D C, Rehkugler G E. Agricultural wheel-tractor overturns. Part II: Mathematical model verification by scale-model study. Transactions of the ASAE, 1974; 17(3): 484-488, 492.

[11] Zeng D, Zhu Y, Zhou Y. A mathematical model for sideways overturning performance of tractor and trailer combinations. Journal of Terramechanics, 1989; 26(3-4): 193-200.

[12] Rehkugler G E, Kumar V, Davis D C. Simulation of tractor accidents and overturns. Transactions of the ASAE, 1976; 19(4): 602-609.

[13] Kayacan E, Kayacan E, Ramon H, Saeys W. Nonlinear modeling and identification of an autonomous tractor-trailer system. Computers and Electronics in Agriculture, 2014; 106: 1-10.

[14] Kolator B, Białobrzewski I. A simulation model of 2WD tractor performance. Computers and Electronics in Agriculture, 2011; 76(2): 231-239.

[15] Larson D L, Smith D W, Liljedahl J B. The dynamics of three-dimensional tractor motion. Transactions of the ASAE, 1976; 19(1): 195-200.

[16] Ahmadi I. Development of a tractor dynamic stability index calculator utilizing some tractor specifications. Turkish Journal of Agriculture and Forestry, 2013; 37(2): 203-211.

[17] Liu B, Koc A B. SafeDriving: A mobile application for tractor rollover detection and emergency reporting. Computers and Electronics in Agriculture, 2013; 98: 117-120.

[18] Liu J, Ayers P D. Application of a tractor stability index for protective structure deployment. Journal of Agricultural Safety and Health, 1998; S1(1): 171-181.

[19] Rabbani M A, Takeoka S, Mitsuoka M, Inoue E, Fukushima T, Okayasu T Simulation for vertical dynamic loading forces on track rollers of the half-tracked tractor based on nonlinear Voigt's model. Engineering in Agriculture, Environment and Food, 2010; 3(4): 119-126.

[20] Vidoni R, Bietresato M, Gasparetto A, Mazzetto F. Evaluation and stability comparison of different vehicle configurations for robotic agricultural operations on side-slopes. Biosystems Engineering, 2015; 129: 197-211.

[21] Yang J H, Sakai H, Murayama S. Side over-turning of articulated-frame skidder running along a contour line. Journal of the Japanese Forestry Society, 1991; 73(1): 1-10.

[22] Yisa M G, Terao H, Noguchi N, Kubota M. Stability criteria for tractor-implement operation on slopes. Journal of Terramechanics, 1998; 35(1): 1-19

[23] Bietresato M, Carabin G, Vidoni R, Mazzetto F, Gasparetto A. A parametric approach for evaluating the stability of agricultural tractors using implements during side-slope activities. Contemporary Engineering Sciences, 2015; 8(28): 1289-1309.

[24] Ahmadi I. Dynamics of tractor lateral overturn on slopes under the influence of position disturbances (model development). Journal of 
Terramechanics, 2011; 48(5): 339-346.

[25] Chisholm C J. The effect of parameter variation on tractor overturning and impact behaviour. Journal of Agricultural Engineering Research, 1979; 24(4): 417-440.

[26] Crolla D A, Horton D N L. Factors affecting the dynamic behaviour of higher speed agricultural vehicles. Journal of Agricultural Engineering Research, 1984; 30: 277-288.

[27] Franceschetti B, Lenain R, Rondelli V. Comparison between a rollover tractor dynamic model and actual lateral tests. Biosystems Engineering, 2014; 127: 79-91.

[28] Gilfillan G. Tractor behaviour during motion uphill: I. Factors affecting behaviour. Journal of Agricultural Engineering Research, 1970; 15(3): 221-235.

[29] Gilfillan G. Tractor behaviour during motion uphill: II. Comparisons of behaviour. Journal of Agricultural Engineering Research, 1970; 15(3): 236-243.

[30] Gravalos I, Gialamas T, Loutridis S, Moshou D, Kateris D, Xyradakis P, et al. An experimental study on the impact of the rear track width on the stability of agricultural tractors using a test bench. Journal of Terramechanics, 2011; 48(4): 319-323.

[31] Guzzomi A L, Rondelli V. Narrow-track wheeled agricultural tractor parameter variation. Journal of Agricultural Safety and Health, 2013; 19(4): 237-260.

[32] Lines J A, Murphy K. The radial damping of agricultural tractor tyres. Journal of Terramechanics, 1991; 28(2-3): 229-241.

[33] Lines J A, Murphy K. The stiffness of agricultural tractor tyres. Journal of Terramechanics, 1991; 28(1): 49-64.

[34] Lines J A, Peachey R O, Collins T S. Predicting the ride vibration of an unsuspended tractor using the dynamic characteristics of rolling tyres. Journal of Terramechanics, 1992; 29(3): 307-315.

[35] Lines J A, Young N A. A machine for measuring the suspension characteristics of agricultural tyres. Journal of Terramechanics, 1989; 26(3-4): 201-210.

[36] Nguyen V N, Matsuo T, Koumoto T, Inaba S. Measurement of the properties of agricultural tire for tractor dynamic analyses (Part 1) Determination of drive tire stiffness and damping from static tests. Journal of the Japanese Society of Agricultural Machinery, 2009; 71(6): $55-62$.
[37] Nguyen V N, Matsuo T, Koumoto T, Inaba S. Measurement of the properties of agricultural tire for tractor dynamic analyses (Part 2) Determination of drive tire stiffness and damping from dynamic tests. Journal of the Japanese Society of Agricultural Machinery, 2009; 71(6): 63-70.

[38] Karkee M, Steward B L. Local and global sensitivity analysis of a tractor and single axle grain cart dynamic system model. Biosystems Engineering, 2010; 106(4): 352-366.

[39] Li Z, Mitsuoka M, Inoue E, Okayasu T, Hirai Y. Development of stability indicators for dynamic Phase I overturn of conventional farm tractors with front axle pivot. Biosystems Engineering, 2015; 134: 55-67.

[40] Taghavifar H, Modarres Motlagh A, Mardani A, Hassanpour A, Haji Hosseinloo A, Wei C. The induced shock and impact force as affected by the obstacle geometric factors during tire-obstacle collision dynamics. Measurement, 2016; 84: 47-55

[41] Takeda J, Shimada M, Kikuchi Y, Nakano M, Okada S, Hiroma T, et al Dynamic Behaviors of Farm Tractor Passing over an Obstacle (Part 1) Improvement of Tractor Dynamic Model and Measurement of Tire Stiffness. Journal of the Japanese Society of Agricultural Machinery, 2010; 72(5): 457-463.

[42] Takeda J, Shimada M, Kikuchi Y, Nakano M, Okada S, Hiroma T, et al. Dynamic behaviors of farm tractor passing over an obstacle (part 2) analysis on validation for improved dynamic model. Journal of the Japanese Society of Agricultural Machinery, 2010; 72(5): 464-470.

[43] International Organization for Standardization. ISO 8608: Mechanical vibration - Road surface profiles - Reporting of measured data. 2016 Genève, Switzerland.

[44] Li Z, Mitsuoka M, Inoue E, Okayasu T, Hirai Y, Zhu Z. Parameter sensitivity for tractor lateral stability against Phase I overturn on random road surfaces. Biosystems Engineering, 2016; 150: 10-23.

[45] Matthews J. Ride comfort for tractor operators. Journal of Agricultural Engineering Research, 1966; 11(1): 44-57.

[46] Ohmiya K. Studies on roughness of meadow. Memoirs of the Research Faculty of Agriculture, Hokkaido University, 1990; 17(2): 151-209.

[47] Torisu R, Matsuo M, Morishima S. Characteristics of the agricultural surface undulations as origins of farm tractor vibrations. Science Bulletin of the Faculty of Agriculture, Kyushu University, 1979; 34(1-2): 7-17. 